\title{
Cooling history of a tholeiitic basalt from Funagata volcano deduced from microstructures of minerals
}

\author{
Akira Miyake and Norimasa ShIMOBayashi \\ Department of Geology and Mineralogy, Graduate School of Science, Kyoto University, Sakyo, Kyoto \\ 606-8502, Japan
}

\begin{abstract}
Cooling history of a tholeiitic basalt from the Kurohana area in Funagata volcano is inferred from the microstructures of clinopyroxene and plagioclase. The sample contains pigeonite, orthopyroxene, olivine and plagioclase as phenocrysts. The phenocrysts are surrounded by the overgrown rims. From the compositional difference between phenocrysts and the overgrown rims, the crystallization sequence has been divided into two stages. At the first stage, the phenocrysts of pyroxene and plagioclase crystallized at above $1473 \mathrm{~K}$ in the magma chamber. They were kept in the chamber less than half a year, which was determined on a basis of the coarsening kinetics of pigeonite-augite intergrowth. Then, at the second stage, the rims of phenocrysts overgrew and groundmass minerals crystallized during the rapid cooling after the eruption. The cooling duration was estimated as about 4-5 years from the size of antiphase domains in plagioclase.
\end{abstract}

\section{Introduction}

Microstructures of some rock-forming minerals contained in an igneous rock provide an information on the thermal history of the rock. Among them, $\mathrm{Ca}-\mathrm{Mg}-$ Fe pyroxene and plagioclase are of importance not only for their abundant occurrence but also for their various microstructures. Each of them has a wide range of chemical composition and a variety of polymorphs, and hence often shows various exsolution textures due to the compositional immiscibilities and the antiphase domain (APD) structures due to the phase transition. Such microstructures are produced during the cooling and closely related to the cooling rate. Therefore, a number of studies have been carried out by focussing upon the relationship between the microstructure and the cooling rate in particular. The relationships between the cooling rates and the sizes of APDs have been extensively examined, for example, in pigeonite (Ghose et al., 1972; Lally et al., 1975; Grove, 1979; Carpenter, 1979) and in plagioclase (Kroll and Müller, 1980; Carpenter, 1991). Carpenter (1979), however, showed that the coarsening

\footnotetext{
A. Miyake, 三宅 亮, miya @ kueps.kyoto-u.ac.jp

N. Shimobayashi, 下林典正, shimo@ kueps.kyoto-u.ac.jp

Corresponding author
}

of APDs in pigeonite is governed by a complex rate law and suggests that the size of APDs does not depend on only the cooling rate but also on the concentration of $\mathrm{Ca}$ ions. Fujino et al. (1988) suggested that the orientation of antiphase boundaries (APBs) in pigeonite lamellae, rather than the size of APDs, would be closely associated with the cooling rate. Moreover, Nord et al. (1973) showed that the size of b-APDs in a single grain of plagioclase varies by an order of magnitude due to the small difference in chemical composition $(\sim 10 \%$ of $\mathrm{An})$. It may be quite difficult to estimate the cooling rate of a rock only from the size of APDs without taking the chemical variation in a fine scale into consideration. In the present study, therefore, we determine the chemical composition of the regions, where the size of APDs was practically measured, in a fine scale by using an analytical electron microscope (AEM).

Recently, the cooling rates of chondrules were estimated from the microstructure of clinopyroxene and plagioclase (Weinbruch and Müller 1995). They obtained the cooling rates by comparing their observed wavelength of pigeonite-augite exsolution lamellae and the size of b-APDs in plagioclase with experimental data of McCallister (1978) and Carpenter (1991), respectively. Such an attempt, however, seems to have been fully applied to terrestrial rocks. In this paper, the cooling history of a terrestrial rock is inferred from the 
microstructures of clinopyroxene and plagioclase coexisting in a pigeonite-bearing basaltic rock as an example.

\section{Sample description}

The sample used in the present study is a tholeiitic basalt collected around the top of Mt. Kurohana in Funagata volcano, located at about $35 \mathrm{~km}$ northwest from Sendai City, Miyagi Prefecture. Funagata volcano belongs to the Nasu volcanic zone and is situated on the volcanic front of the northeast Japan arc. Mt. Kurohana is situated at the southern end of Funagata volcano (see Fig. 1 in Wada, 1981), and erupted at the first stage (the Quaternary period) of the volcanic activity of the Funagata volcano (Wada, 1981). Aoki (1961) first reported that some basalts from the Kurohana area contain rather large ( $2 \mathrm{~mm}$ in maximum size) pigeonite phenocrysts. Aoki (1961) further classified the pigeonite-bearing basalts from this area into two types by the existence and nonexistence of augite phenocrysts, and has suggested that the latter type represents the composition of the primary tholeiitic magma of the Nasu zone.

The phenocryst assemblage of the present sample is olivine, plagioclase, pigeonite and orthopyroxene and the groundmass consists of plagioclase, augite and opaque minerals. This corresponds to the latter type classified by Aoki (1965) or 'Type 1 sample' described by Fujinawa (1982) because of the lack of augite phenocrysts. Petrographical characteristics and chemical compositions of each phenocryst and groundmass minerals are descried below.

Pyroxene; Both phenocrysts of pigeonite and orthopyroxene are idiomorphic or hypidiomorphic, and columnar ( $3 \mathrm{~mm}$ in maximum size). They have a remarkable difference in brightness in back-scattered electron images (BEI's) between the core and the overgrown rim separated by sharp boundaries, but no difference in brightness was observed in the core. Microprobe analysis of pyroxenes was carried out and the results are plotted on a pyroxene quadrilateral (Fig. 1a). The core of the pigeonite phenocryst is homogeneous (about $\mathrm{Wo}_{9} \mathrm{En}_{71} \mathrm{Fs}_{20}$ ) and the core of the orthopyroxene phenocryst is also homogeneous (about $\left.\mathrm{Wo}_{5} \mathrm{En}_{77} \mathrm{Fs}_{18}\right)$. Both phenocrysts of pigeonite and orthopyroxene have chemical compositional gaps between the cores and the rims. The rims of them have the compositional zoning, and this compositional zoning trend shows that the Fs component increases outwards from $\mathrm{Fs}_{20}$ to $\mathrm{Fs}_{60}$ at a constant Wo component $\left(\mathrm{Wo}_{25-35}\right)$. The chemical composition of augite in the
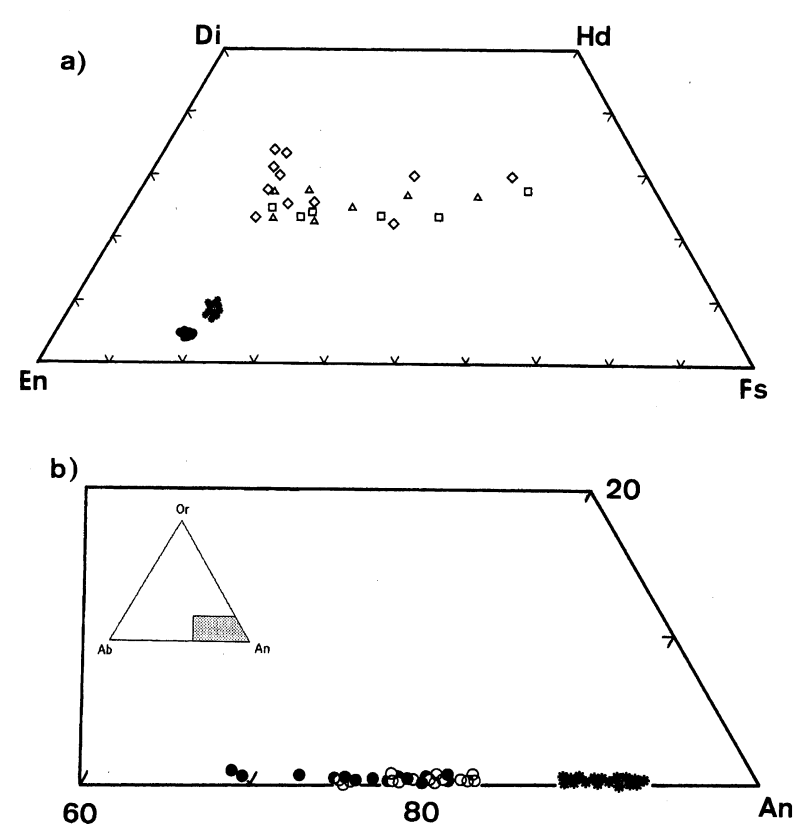

Figure 1. Chemical compositions of a) pyroxenes and b) plagioclases in the present sample. a) Solid circles and crosses represent the data from orthopyroxene and pigeonite phenocrysts, respectively. Open symbols represent subcalsic augite overgrown around orthopyroxene (square) and pigeonite (triangle), respectively, and in the groundmass (diamond). b) Asterisks and open and solid circles represent the data from plagioclase phenocryst, the overgrown rims and groundmass grains, respectively.

groundmass is similar to that of the overgrown rims.

Olivine; Olivine phenocrysts exhibit a hypidiomorphic or xenomorphic nature. The largest olivine phenocryst has a length of about $1 \mathrm{~mm}$. They are always surrounded by fayalite-rich rims.

Plagioclase; Plagioclase phenocrysts are idiomorphic or hypidiomorphic and columnar (3 $\mathrm{mm}$ in maximum size). A zonal structure is observed in the inner part of a few phenocrysts. Each plagioclase phenocryst has a remarkable difference in brightness between the core and the rim separated by a sharp boundary. A zonal structure was observed with an optical microscope, but there is no difference in brightness within the core under the BEI. Microprobe analysis was carried out and the results are shown in Figure 1b. The core of the plagioclase phenocryst is homogeneous (about $\mathrm{An}_{92} \mathrm{Ab}_{8}$ ).

Plagioclase phenocrysts had the chemical compositional gap between the core and their rims. The chemical composition of plagioclase in a groundmass $\left(\mathrm{An}_{70-82}\right)$ was similar to that of the rim of the plagioclase phenocryst $\left(\mathrm{An}_{74-83}\right)$. 


\section{Microstructures of pyroxene and plagioclase}

Some phenocrysts of pigeonite, orthopyroxene and plagioclase were selected for the TEM study. The selected phenocrysts were removed in company with their overgrown rims from petrographic thin sections and sandwiched by $\mathrm{Cu}$ grids of $3 \mathrm{~mm}$ diameter. They were further thinned by ion beam bombardment. Some grains of augite and plagioclase in the groundmass were also prepared in the same manner. Observations were made with a HITACHI H-8000 microscope operating at $200 \mathrm{KV}$. The microchemistry of the minerals was determined by AEM combined with an energy dispersive X-ray microanalyser (Kevex Delta series).

Pyroxenes; Observations were performed mainly with a dark-field imaging technique using a class $b$ reflection $(h+k=o d d)$. No significant microstructure is observed in orthopyroxene phenocrysts (Fig. 2a), while all the observed clinopyroxenes (including overgrown rims)
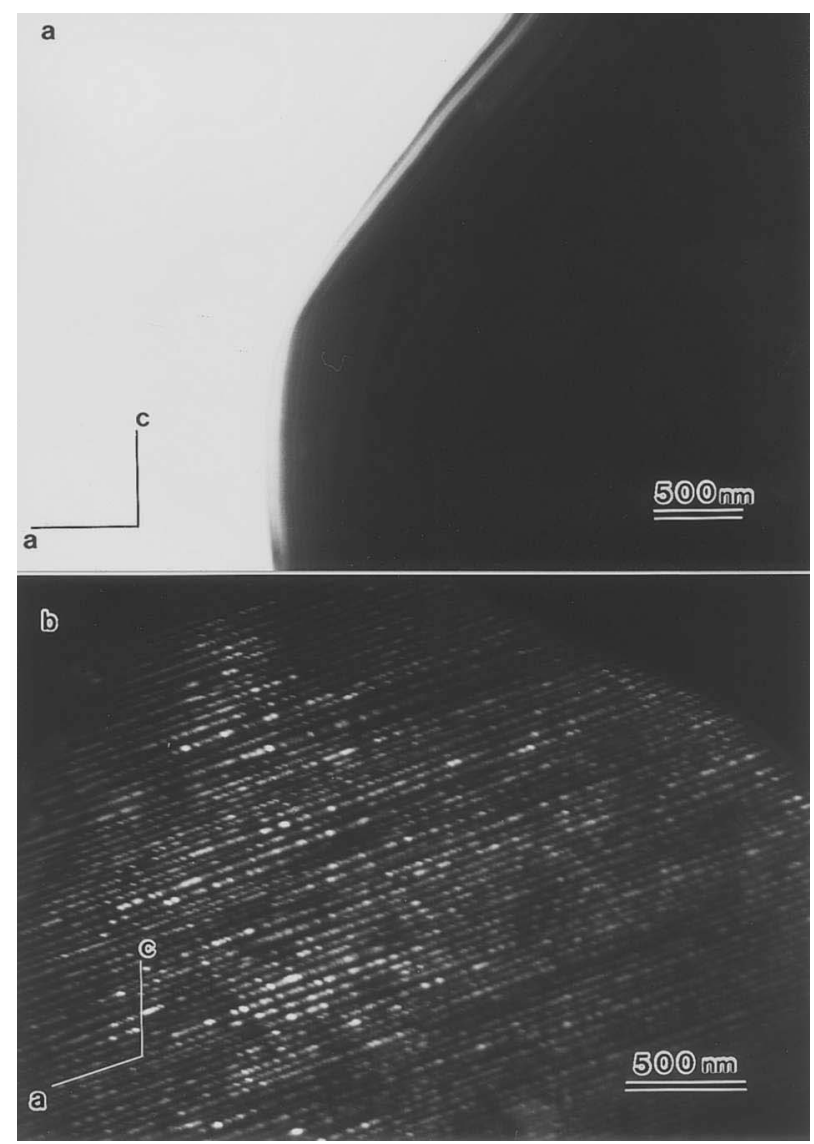

Figure 2. (a) Bright-field electron micrograph of an orthopyroxene phenocryst and (b) dark-field micrograph $(g=50 \overline{2})$ of its overgrown rim. No microstructure is observed in (a) while pigeonite-augite exsolution lamellae are developed on (001) in (b).
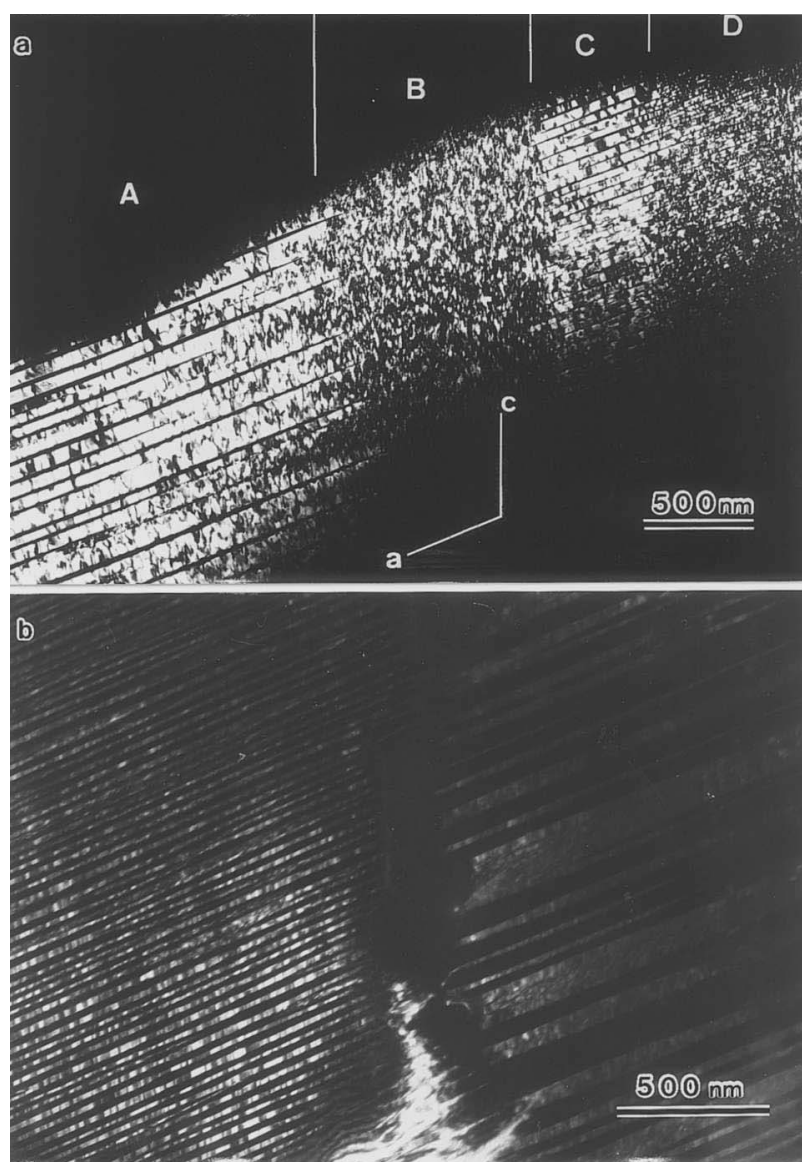

Figure 3. Dark-field electron micrograph $(g=102)$ taken from (a) a pigeonite phenocryst and (b) its overgrown rim. Both micrographs display pigeonite-augite exsolution lamellae on (001) and the APD structure in pigeonite lamellae. The pigeonite phenocryst shows zonal structure with regard to the thickness of augite lamellae and can be divided into four zones (A-D) in the figure (a).

display (001) exsolution textures and APD structures (Figs. 2b, 3 and 4). A typical example of such microstructures in pigeonite phenocrysts is shown in Figure 3a. The pigeonite-augite lamellae are predominant intergrown on (001), and (100) lamellae are very scarce. The (001) exsolution lamellae look like having been developed from periodic fluctuations and often slightly waved, indicating a formation by the mechanism of spinodal decomposition and subsequently coarsening. From a feature of the microstructure, the area observed in this figure can be divided into four zones as summarized in Table 1. Average lamella wavelengths of augite-pigeonite intergrowth are measured as approximately $20-60 \mathrm{~nm}$ in this area. Müller (1991) reported that the size of APDs in pigeonite decreases and the wavelength of modulated pigeonite-augite intergrowth increases with increasing the $\mathrm{Ca}-$ content. The present observation, however, conflicts with his description in 
Table 1. Average wavelength of the pigeonite-augite exsolution lamellae on (001) and the size APDs observed within each zone in Figure $3 \mathrm{a}$

\begin{tabular}{|c|c|c|c|c|}
\hline Zone & A & $\mathrm{B}$ & $\mathrm{C}$ & $\mathrm{D}$ \\
\hline Chemical composition (mol \% of Wo) & 11.4 & 8.6 & 10.5 & 10.2 \\
\hline Average wavelength of pig-aug intergrowth ( $\lambda \mathrm{nm})$ & 62 & 0 & 43 & 18 \\
\hline Average size of APDs $\left(\mathrm{nm}^{2}\right)$ & 900 & 780 & 850 & 250 \\
\hline
\end{tabular}

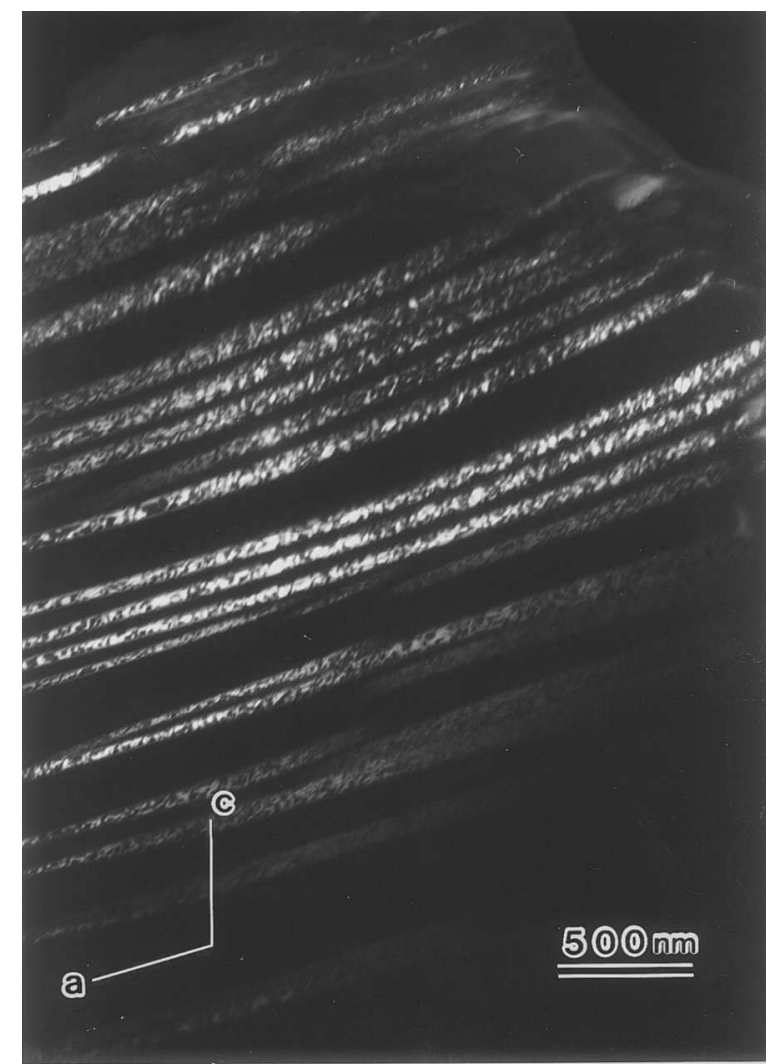

Figure 4. Dark-field electron micrograph $(g=302)$ taken from a augite grain in the groundmass.

respect of the relationship between the size of APDs and Ca-content.

In the overgrown rims around orthopyroxene (Fig. 2b) and pigeonite (Fig. 3b), (001) augite exsolution lamellae formed by spinodal decomposition were observed and APD structures were observed in pigeonite lamella. The similar microstructures were also observed in the groundmass augite (Fig. 4).

Plagioclase; Electron diffraction patterns from the plagioclase phenocrysts consist of class $a, b$ and $c$ reflections (class $a: h+k=$ even, $l=e v e n$; class $b: h+$ $k=$ odd, $l=o d d$; class $c: h+k=$ even, $l=o d d$ or $h+$ $k=o d d, l=e v e n)$. Both class $a$ and $b$ reflections are sharp but the class $c$ reflection is diffuse. No b-APBs were observed in the dark field images using the class $b$ reflection (Fig. 5a). Dark field images using the class $c$
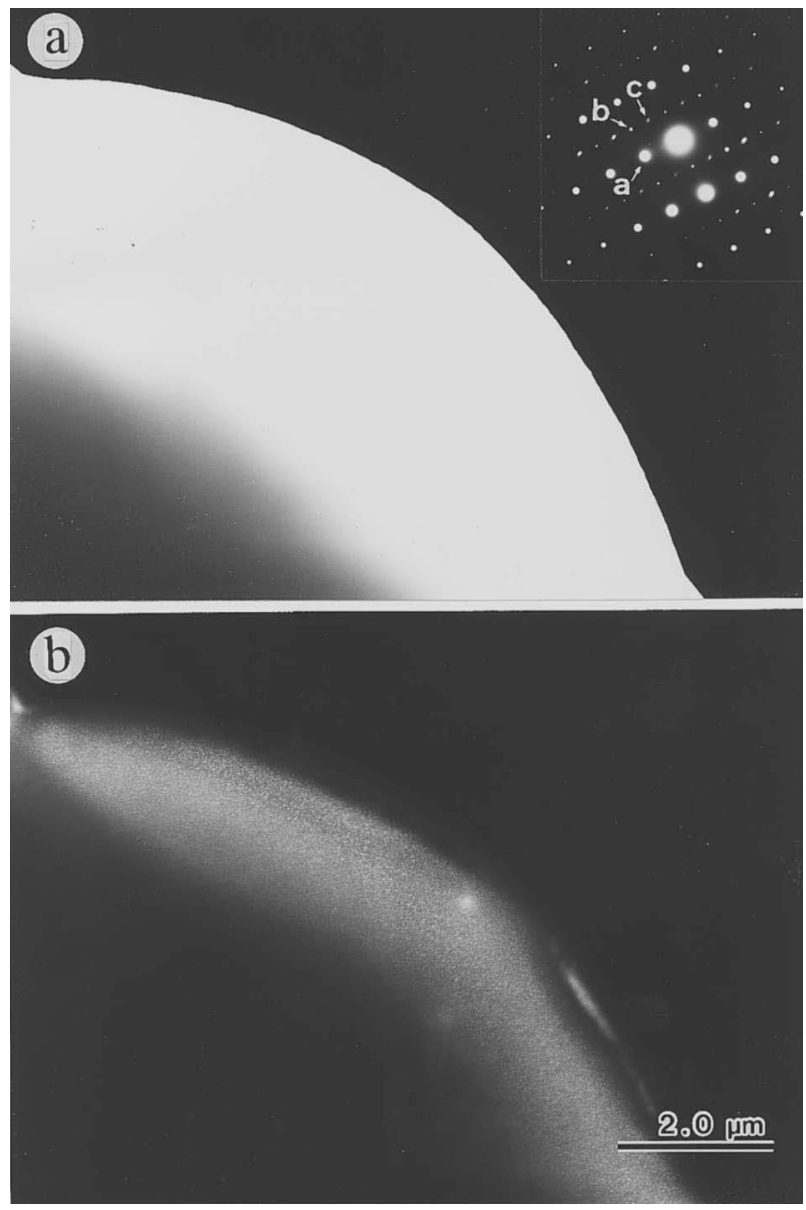

Figure 5. A set of dark-field electron micrographs; (a) using a class $b$ reflection $(g=1 \overline{4} 1)$ and (b) a class $c$ reflection $(g=$ $15 \overline{1})$, and electron diffraction pattern taken from a plagioclase phenocryst. Class $a, b$ and $c$ reflections appear in the diffraction pattern indicating $\mathrm{P} \overline{1}$ anorthite. Type $b$-APDs are not observed in (a) while very fine c-APDs are observed in (b).

reflection, on the other hand, revealed a presence of a numerous number of fine c-APDs (Fig. 5b).

Electron diffraction patterns from the overgrown rims consist of sharp class $a$ and $b$ reflections. Type b-APDs were observed in the dark field image using the class $b$ reflection (Fig. 6). The average size of b-APDs is determined as about $1.0 \times 10^{4} \mathrm{~nm}^{2}$ (Table 2).

Electron diffraction patterns from the groundmass plagioclases consist of sharp class $a$ and $b$ reflections. 
Table 2. Average size of $\mathrm{b}-\mathrm{APDs}(\mathrm{S})$ and the estimated cooling time scale $(\tau)$ deduced from an overgrown rim and a single grain of plagioclase in the groundmass

\begin{tabular}{ccccc}
\hline Region & $\begin{array}{r}\text { Chemical composition } \\
(\text { mole \%) }\end{array}$ & $\begin{array}{r}\text { Average size of } \\
\text { b-APDs }(\mathrm{S})\end{array}$ & $\mathrm{T}_{\mathrm{e}}$ & Cooling time scale $(\tau)$ \\
\hline rim (Figure 6) & $\sim \mathrm{An} 74$ & $1.0 \times 10^{4} \mathrm{~nm}^{2}$ & $1654 \mathrm{~K}$ & $1.1 \times 10^{4} \mathrm{hrs}$. \\
$\alpha$ (Figure 7) & $\sim \mathrm{An} 71$ & $3.2 \times 10^{3} \mathrm{~nm}^{2}$ & $1562 \mathrm{~K}$ & $3.4 \times 10^{4} \mathrm{hrs.}$ \\
$\beta$ (Figure 7) & $\sim \mathrm{An73}$ & $2.2 \times 10^{4} \mathrm{~nm}^{2}$ & $1623 \mathrm{~K}$ & $4.6 \times 10^{4} \mathrm{hrs}$. \\
$\gamma$ (Figure 7) & $\sim \mathrm{An} 82$ & $>7.0 \times 10^{5} \mathrm{~nm}^{2}$ & $1900 \mathrm{~K}$ & $>0.53 \times 10^{4} \mathrm{hrs}$. \\
\hline
\end{tabular}

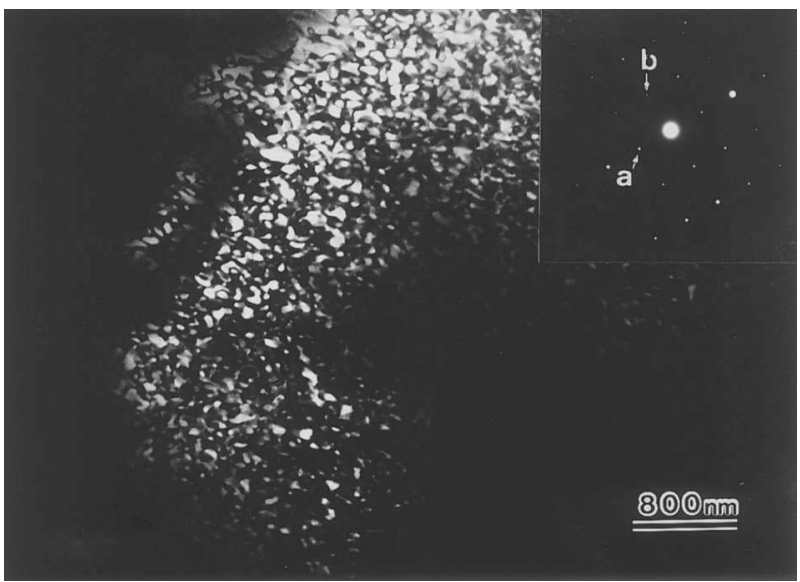

Figure 6. Dark-field electron micrograph of the overgrown rim around the plagioclase phenocryst, taken with a $b$ reflection $(g=141)$. Type b-APDs are observed and their average size in this figure is approximately $1.0 \times 10^{4} \mathrm{~nm}^{2}$.

The $b$-APDs were observed in the dark field images using the class $b$ reflection at three different regions in the same specimen (Fig. 7). The average size of $b-$ APD varies with chemical compositions even in a single grain. For example, the average size of b-APD is $3.2 \times$ $10^{3} \mathrm{~nm}^{2}$ in the region $\alpha, 2.2 \times 10^{4} \mathrm{~nm}^{2}$ in the region $\beta$, and larger than $7 \times 10^{5} \mathrm{~nm}^{2}$ in the region $\gamma$. The size in the region $\gamma$ should be actually larger than $7 \times 10^{5} \mathrm{~nm}^{2}$ because it is too large to measure where b-APDs. Microanalysis of these three regions was performed and the results are summarized in Table 2 in company with the size of $b$-APDs.

\section{Discussion}

\section{Two stages of crystallization sequence}

The present sample has the same petrographical characteristics as those of the 'Type 1 sample' of Fujinawa (1982). He divided the crystallization sequence of the 'Type 1 sample' into two stages; that is, at the first stage phenocrysts crystallized in the magma chamber and at the second stage the subcalsic-augite overgrew around the pyroxene phenocrysts and the groundmass minerals crystallized at almost the same time. The present study reveals that every phenocryst of pyroxenes (pigeonite and orthopyroxene) has the homogeneous core part and the $\mathrm{Ca}$-rich rim separated by the sharp boundaries. The overgrown rims have a wide range of chemical composition but the distribution of the analyzed data almost overlaps with that of augite in the groundmass (Fig. 1a). The same tendency of chemical zoning trend is recognized in plagioclase. In addition, b-APDs can be observed in both the overgrown rims and groundmass plagioclases but could not be observed in the plagioclase phenocrysts. Consequently, the crystallization sequence of the present basalt sample can be divided into two stages as pointed out by Fujinawa (1982).

(1) The 1st stage; At this stage the phenocrysts of pyroxenes (pigeonite and orthopyroxene) and plagioclase crystallized in the magma chamber. Fujinawa (1982) estimated the crystallization temperature in the chamber as above about $1473 \mathrm{~K}$ from the three pyroxene geothermometer. At this temperature pigeonite must have crystallized as a high-temperature polymorph with $\mathrm{C} 2 / \mathrm{c}$ symmetry because the transition temperature of the present pigeonite $\left(\mathrm{Wo}_{9} \mathrm{En}_{71} \mathrm{Fs}_{20}\right)$ can be estimated as 1273-1373K from the diagram of Prewitt et al. (1971).

The presence of fine c-APDs (Fig. 5b) indicates that the plagioclase phenocrysts should have crystallized as the $\mathrm{I} \overline{1}$ phase and then transformed into the $\mathrm{P} \bar{l}$ phase. Unfortunately, however, no useful constraint can be obtained to the crystallization temperature because anorthitic plagioclase has I 1 symmetry from approximately $500 \mathrm{~K}$ to the melting point (about $1800 \mathrm{~K}$ ) under equilibrium conditions.

If the pigeonite phenocrysts were kept in the magma chamber for the long time after their crystallization, the coarsening of pigeonite-augite intergrowth should occur due to the diffusion of $\mathrm{Ca}$ ions. The coarsening kinetics of (001) exsolution lamellae in clinopyroxene $\left(\mathrm{Wo}_{27} \mathrm{En}_{73}\right)$ was studied by McCallister (1978) at temperatures of 1573,1473 and $1373 \mathrm{~K}$. The isothermal coarsening kinetics of the lamellae was found to follow a rate law; $\lambda=\lambda_{0}+k t^{1 / 3}$ where $\lambda$ is the wavelength of the 

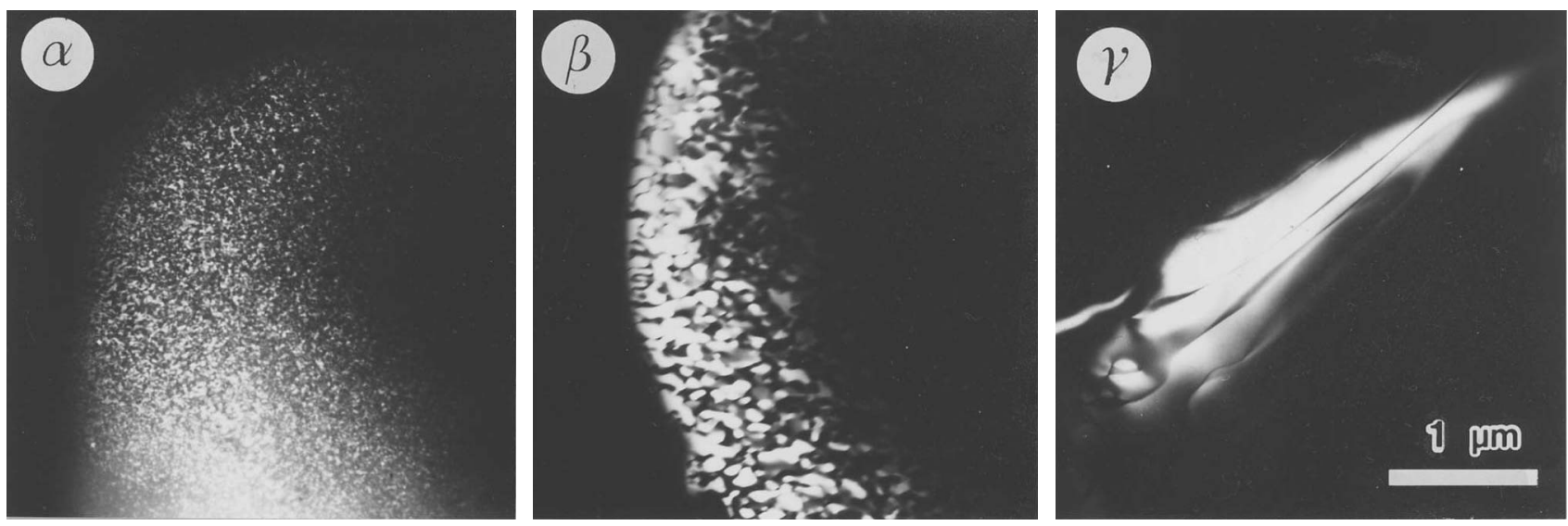

Figure 7. A set of dark-field micrographs taken from three regions in the same grain in groundmass plagioclase. The average sizes of b-APDs in these regions are measured as $3.2 \times 10^{3} \mathrm{~nm}^{2}(\alpha), 2.2 \times 10^{4} \mathrm{~nm}^{2}(\beta)$ and much larger than $7 \times 10^{5} \mathrm{~nm}^{2}(\gamma)$, respectively

exsolution lamellae, $\lambda_{0}$ is the initial wavelength, $k$ is a constant and $t$ is the annealing time in days. By assuming that the temperature in the magma chamber is constant to be $1473 \mathrm{~K}$, that the initial wavelength $\left(\lambda_{0}\right)$ is negligible, and that $k$ does not depend upon the composition, the annealing time of $2^{3}-6^{3}$ days was deduced from Figure 2 of McCallister (1978) for the present pigeonite phenocryst (Table 1). Consequently, the eruption should have occurred within half a year after the crystallization of the phenocrysts in the magma chamber.

(2) The 2nd stage; At this stage overgrown rims and groundmass minerals crystallized during the cooling after the eruption. The presence of $b$-APDs in the overgrown rims and groundmass plagioclase indicates that they crystallized as the $C \overline{1}$ phase and then transformed to the Ii phase. Because the stability field of the $\mathrm{C} \overline{1}$ phase for these plagioclases $\left(\mathrm{An}_{70-83}\right)$ is above $1900 \mathrm{~K}$ (exceeding the melting point), they should have been formed metastably as the $C \overline{1}$ phase in the stability field of the I $\overline{1}$ phase during the rapid cooling. Weinbruch and Müller (1995) described that the disordered Cī structure occurs metastably when anorthite is formed at temperatures between approximately $1773 \mathrm{~K}$ and $1273 \mathrm{~K}$.

The APD structure observed in pigeonite should be formed during the cooling at this stage. As seen in Figure 3, APDs in pigeonite lamellae seem to be elongated along the c axis, which implies qualitatively a rapid cooling as pointed out by Fujino et al. (1988) or Shimobayashi (1992). The size of b-APDs in plagioclase is considered to be more useful for determining geological cooling rates. However, its usefulness is complicated by the fact that the domain size varies by an order of magnitude depending upon the small chemical variation $(\sim 10 \%$ of $\mathrm{An})$ in a single grain even at a constant cooling rate (Nord et al., 1973). Heuer and Nord (1976) attributed the variation of the domain size with composition to a difference in the transition temperature with composition. But, the relationship between the size and cooling rate was not formulated. In the next section, we discuss on the cooling time scale at this stage.

\section{Estimation of cooling time scale}

In the case of isothermal coarsening of domains (for example, annealing of metals or alloys), a rate law of the following form has been well-established;

$$
\delta^{n}-\delta_{0}^{n}=n \cdot k_{0} \cdot \exp (-H / R T) \cdot\left(t-t_{0}\right)
$$

where $\delta$ is the average domain diameter at $t, \delta_{0}$ the initial domain diameter at time $t_{0}, H$ the activation energy, $R$ the gas constant, and $n$ and $k_{0}$ constants. The rate law indicates that the domain size becomes larger at higher temperature in a constant duration, or with the longer duration at the constant temperature.

In the present study, we shall discuss more quantitatively on the relationship between the b-APD size and the composition on a basis of the equation (1), although temperature had actually been changing with time in the cooling history. By dividing the cooling path into time-segments during which isothermal reactions can be applied and then the equation (1) can be adopted, and by integrating these segments over the whole cooling path, the equation (2) can be derived;

$$
\delta^{n}=\int_{0}^{t} n \cdot k_{0} \cdot \exp (-H / R T) d t
$$

where the time when the system reached down to the phase transition temperature $T_{e}$ is regarded as $t=0$, and then $\delta_{0}$ is assumed to be negligible. 
As mentioned above, the equation (2) is based on the fact that the cooling path crosses the phase boundary separating the $C \overline{1}$ and $I \overline{1}$ phases. However, the present plagioclase in the groundmass under consideration is considered to crystallize metastably as the Cì phase in the stability field of the $\mathrm{I} \overline{\mathrm{l}}$ phase. Although the assumption that the equation (2) can hold in such a case is forcible, in the present study, we estimated as a first approximation, the cooling rates by using the equation (2). Carpenter (1991) measured an average b-APD size $(\delta)$ as the average spacing between APBs measured along the lines randomly drawn on the micrograph. On the other hand, in this study an average b-APD size is measured as the area $(S)$. To simplify, the relationship between $S$ and $\delta$ is assumed as $S=\delta^{2}$. The final size of $b$-APDs is approximately given below with the cooling time scale, $\tau$, as introduced into the diffusioncontrolled reaction between solid and gas in the cooling nebula by Hasegawa (1984),

$$
S^{\frac{n}{2}} \approx n \cdot k_{0} \cdot \exp \left(-H / R t_{e}\right) \cdot \frac{R T_{e}}{H} \cdot \tau
$$

where $T_{e}$ is the phase transition temperature and $\tau$ given by the equation;

$$
\tau=\left|\frac{d \ln T}{d t}\right|_{T=T_{e}}^{-1}
$$

If cooling occurs in the same manner, the cooling time $\tau$ is expected to be a constant value. Assuming that the cooling occurred exponentially, $\tau$ means the duration within which the temperature decreased to $1 / e$ of $T e$ (K). The $\mathrm{C} \overline{1}-\mathrm{I} \overline{1}$ transformation temperature $T_{e}(x)$ at $x$, the anorthite mol \% is estimated from the phase diagram by Carpenter and McConnell (1984) as below;

$$
T_{e}=30.6 \cdot x-610
$$

Therefore, in general, the b-APD coarsening size at $x$ is approximately given by the equation;

$$
\begin{aligned}
S^{\frac{n}{2}}= & n \cdot k_{0} \cdot \exp \left\{\frac{-H}{R \cdot(30.6 \cdot x-610)}\right\} \cdot \\
& \frac{R \cdot(30.6 \cdot x-610) \cdot \tau}{H}
\end{aligned}
$$

Table 2 shows the chemical composition (An component), the transition temperatures derived from the equation (5) and the observed sizes of b-APDs in the rim and in three regions $(\alpha, \beta$, and $\gamma)$ in a single grain of plagioclase in the groundmass. As pointed out by Weinbruch and Müller (1995), the value of $k$ in the paper of Carpenter (1991) was incorrect. Assuming that value of $n, k_{0}$ and $H$ do not depend upon the composition, therefore, in the present study the values were estimated directly from the experimental data of Carpenter (1991) as below; $n=2, k_{0}=3.1 \times 10^{17}\left(\mathrm{~nm}^{2} / \mathrm{h}\right)$ and $H=123$ (kcal). The value of $\tau$ at each region is estimated from the equation (6) and is listed in Table 2. As the result, though the size in the region $\alpha$ is one order of magnitude smaller than that in the region $\beta$, each value of the cooling time $\tau$ in the region $\alpha$ and $\beta$ gives approximately the same value, about $4 \times 10^{4}$ hours (4-5 years). By taking a possibility that we underestimated the domain size in the region $\gamma$ into consideration, the cooling time deduced from the region $\gamma$ is not necessarily inconsistent with an order of $\sim 10^{4}$ hours.

\section{Summary}

The cooling history of the present sample is then concluded as follows.

The crystallization sequence can be divided into two stages. At the first stage, the phenocrysts of pyroxene and plagioclase crystallized at above $1473 \mathrm{~K}$ in the magma chamber and were kept there for less than a half-year. Then, after the eruption, the rims of phenocryst overgrew and groundmass minerals crystallized during the cooling. The cooling time was estimated as about $4-5$ years.

\section{Acknowledgements}

We are grateful to Dr. K. Aoki and Dr. K. Wada for giving the information of the locality of the sample used in the present study. We are also grateful to Dr. M. Kitamura and Dr. K. Fujino for critically reading the manuscript.

\section{References}

Aoki, K. (1961) Early stage basalts from the Nasu volcanic zone. Journal of Mineralogy, Petrology and Economic Geology, 45, 54-65 (in Japanese).

Carpenter, M.A. (1979) Experimental coarsening of antiphase domain in a silicate mineral. Science, 206, 681683.

Carpenter, M.A. (1991) Mechanisms and kinetics of Al-Si ordering in anorthite: 1. Incommensurate structure and domain coarsening. American Mineralogist, 76, 11101119.

Carpenter, M.A. and McConnell, J.D.C. (1984) Experimental delineation of the $C \overline{1} \leftrightarrow I \overline{1}$ transformation in intermediate plagioclase feldspars. American Mineralogist, 69, 112121.

Fujinama, A. (1982) Early stage crystallization differentiation of the island arc tholeiite magma, Nasu volcanic zone, Northeast Japan - A petrological study of 
the Funagata pigeonite basalts - . Journal of Mineralogy, Petrology and Economic Geology, 77, 419-437 (in Japanese).

Fujino, K., Furo, K. and Momoi, H. (1988) Preferred orientation of antiphase boundaries in pigeonite as a cooling ratemater. Physics and Chemistry of Minerals, 15, 329335 .

Ghose, S., Ng, G. and Walter, L.S. (1972) Clinopyroxenes from Apollo 12 and 14 : Exsolution, domain structure and cation order. Proceedings of the Third Lunar Science Conference, 507-531.

Grove, T.L. (1979) An experimental calibration of submicroscopic textures in lunar pyroxenes: a transmission electron microscope study. Lunar Planetary Science, X, 467-469.

Hasegawa, H. (1984) Dust in the universe. In: Hasegawa H. and Obayashi T., editors. Modern Solar System Sciences, 17-47, Univ. Tokyo Press, Tokyo (in Japanese).

Heuer, A.H. and Nord, G.L. JR. (1976) Polymorphic phase transitions in minerals. In Wenk H.R. editor., Electron Microscopy in Mineralogy, 274-303. Springer-Verlag, Berlin Heidelberg New York.

Kroll, H. and Müller, W.F. (1980) X-ray and electron-optical investigation of synthetic high-temperature plagioclase. Physics and Chemistry of Minerals, 5, 255-277.

Lally, J.S., Heuer, A.H., Nord, G.L. Jr., and Christie, J.M. (1975) Sub-solidus reactions in lunar pyroxenes: An electron petrographic study. Contributions to Mineralogy and Petrology, 51, 263-282.

McCallister, R.H. (1978) The coarsening kinetics associated with exsolution in an iron-free clinopyroxene. Contribu- tions to Mineralogy and Petrology, 65, 327-331.

Müller, W.F. (1991) Microstructure of minerals in a chondrule from Allende meteorite. II. Thermal history deduced from clinopyroxenes and other minerals. Neues Jahrbuch fur Mineralogie, Abh., 162, 237-259.

Nord, G.L.Jr., Lally, J.S., Heuer, A.H., Christie, J.M., Radcliffe S.V., Griggs D.T. and Fisher, R.M. (1973) Petrologic study of igneous and metaigneous rocks from Apollo 15 and 16 using high voltage transmission electron microscopy. Proceedings of 4th Lunar Science Conference, 953-970.

Prewitt, C.T., Brown, G.E. and Papike, J.J. (1971) Apollo 12 clinopyroxenes. High temperature $\mathrm{X}$-ray diffraction studies. Proceedings of the Second Lunar Conference, $59-68$.

Shimobayashi, N. (1992) Direct observation on the formation of antiphase domain boundaries in pigeonite. American Mineralogist, 77, 107-114.

Wada, K. (1981) Contrasted petrological relations between tholeiitic and calc-alkalic series from Funagata volcano, northeast Japan. Journal of Mineralogy, Petrology and Economic Geology, 76, 215-232.

Weinbruch, S. and Müller, W.F. (1995) Constraints on the cooling rates of chondrules from the microstructure of clinopyroxene and plagioclase. Geochimica et Cosmochimica Acta, 59, 3221-3230.

Manuscript received; 2 August, 1999

Manuscript accepted; 1 February, 2000 